\title{
Ultrasonography in soft-tissue foreign-body detection: a phantom study
}

\author{
Sermin Tok ${ }^{1 A, B, E, F}$, Emine Kadioglu ${ }^{2 B, C, D, G}$ \\ 'Department of Radiology, Kutahya Health Sciences University, Kutahya, Turkey \\ ${ }^{2}$ Department of Emergency Medicine, Kutahya Health Sciences University, Kutahya, Turkey
}

\section{Abstract}

Purpose: Foreign body implantation into the soft tissues, either in the early period or late period, is a common cause of emergency department admissions. Direct X-rays are preferred in the diagnosis of soft-tissue foreign-bodies. Herein, we aimed to analyse the detection rates of foreign bodies of various sizes placed in phantoms implanted into soft tissue by ultrasonography.

Material and methods: A total of 740 pieces of chicken fillet were prepared as phantoms. No objects were implanted into 100 phantoms. We inserted glass, porcelain, plastic, wood, pencil tip, chicken bone, iron, walnut shell, and fishbone with a length of $<1 \mathrm{~cm}, 1-3 \mathrm{~cm}$, and $3-5 \mathrm{~cm}$ into 20 pieces of chicken phantom in each size of foreign body (FB). In addition, $1-3 \mathrm{~cm}$ long peanut shell, $<1 \mathrm{~cm}$ rose spikes, $<1 \mathrm{~cm}$ cactus thorns, $<1 \mathrm{~cm}$ pellets, and $<1 \mathrm{~cm}$ staples were inserted into 20 pieces of chicken for each object. Each of the chicken pieces was placed inside a latex glove and examined by ultrasonography.

Results: The sensitivity of ultrasonography in the detection of the cactus thorn was $5 \%$, whereas it ranged between 82.5 and $100 \%$ for other objects. For glass, plastic, wood, iron, and fishbone, we found that when the size exceeded $1 \mathrm{~cm}$, the sensitivity increased.

Conclusions: In the evaluation of soft tissue FBs, as the size of the FBs increases, the diagnostic value of ultrasonography increases.

Key words: chicken model, foreign bodies, phantom, soft tissue, ultrasonography.

\section{Introduction}

Foreign body implantation into soft tissues, either in the early period or late period, is a common cause of emergency department admissions. Infection, chronic pain, and fibrosis are frequent late complications in this patient group. Direct X-rays are preferred in the diagnosis of soft-tissue foreign-bodies (FBs) [1]. Some of the foreign bodies are visualized as radiopaque on direct X-rays; however, some radiolucent objects such as organic materials cannot be detected by direct X-ray examinations [2-4]. The visualization of an object on X-rays depends on not only its density, but also its size, location, and depth in the soft tissue [5]. Moreover, another disadvantage of direct $\mathrm{X}$-ray examinations is ionizing radiation exposure [5]. Ultrasonography (US) is the second most preferred imaging modality in detecting FBs in soft tissue [5]. In addition to radiopaque materials, some radiolucent materials and the complications of these materials in the tissue can be determined without using ionizing radiation [2]. An important disadvantage of US is that it is a user-dependent modality [5]. However, showing soft-tissue FBs with high detection rates by an ionizing radiation-free method would be very useful in emergency departments.

Correspondence address:

Sermin Tok Umay, Department of Radiology, Kutahya Health Sciences University, Kutahya, Turkey, e-mail: sermintok@hotmail.com

Authors' contribution:

A Study design · B Data collection · C Statistical analysis · D Data interpretation · E Manuscript preparation · F Literature search · G Funds collection 
In this study, we aimed to analyse the US detection rates for various sizes of foreign bodies placed in phantoms implanted into soft tissue.

\section{Material and methods}

\section{Ethical approval}

We conducted our study prospectively on phantoms. This prospective study was approved by the institutional review board of the Ethical Committee of our hospital.

\section{Phantoms}

Parallel to the long axes of the chicken pieces, a $1 \mathrm{~cm}$ deep slit was formed with a knife. A total of 740 pieces of chicken fillets $3 \mathrm{~cm}$ thick, $10 \mathrm{~cm}$ long, and $5 \mathrm{~cm}$ wide were prepared. A total of 20 pieces of glass, porcelain, plastic, wood, pencil-tip, chicken bone, iron, walnut shell, and fishbone, with a height and width $<0.5 \mathrm{~cm}$ and length $<1 \mathrm{~cm}$, $1-3 \mathrm{~cm}$, and $3-5 \mathrm{~cm}$ in rectangular shape were implanted into the slits opened in the chicken pieces, each on a separate chicken piece. In addition, 20 pieces of 1-3 cm long peanut shells, $<1 \mathrm{~cm}$ rose spikes, $<1 \mathrm{~cm}$ cactus spurs, $<1 \mathrm{~cm}$ pellets, and $<1 \mathrm{~cm}$ staples were implanted into chicken pieces separately. The chicken pieces were kept under light compression for 24 hours in order to remove air bubbles. No objects were placed in 100 chicken pieces. Each chicken piece was then placed separately in a latex glove. The latex gloves were filled with ultrasound gel and tied.

\section{The imaging method}

Sonography (Siemens, Acuson S3000, California, USA) was performed using a 5-14 MHz linear transducer. Each phantom was evaluated by a radiologist ( 7 years of experience) and an emergency medicine specialist (8 years of experience). The observers were blinded to the presence and kind of foreign bodies in phantoms. Examinations were carried out in 2 planes, in parallel with the long- and short-axis of the phantom, without time constraint. Each phantom was evaluated twice at 24-hour intervals.

\section{Statistical analysis}

The SPSS 20.0 program and Excel (Microsoft) were used to analyse the data. Sensitivity, specificity, positive predictive value, and negative predictive value were calculated for each body considering the diagnoses of the 2 observers. The inter-observer compliance values were expressed using $\kappa$ statistics. A value of $\kappa$ equal to +1 implies perfect agreement between the 2 observers while that of -1 implies disagreement. If $\kappa$ assumes the value 0 , then this implies that there is no relationship between the ratings of the 2 observers.

\section{Results}

Sensitivity, specificity, positive predictive value, and negative predictive value were calculated for each material. These findings are summarized in Table 1.

Significant differences were detected in the value of fish bones $<3 \mathrm{~cm}$ and $>3 \mathrm{~cm}$ of diagnostic value of US $(p=0.008<0.05)$. There was no significant difference between the diagnosis of US for $<3 \mathrm{~cm}$ and $>3 \mathrm{~cm}$ glass, porcelain, plastic, wood, pencil-type, chicken bone, iron, and walnut shell $(p>0.05)$; therefore, the diagnostic value of ultrasound is high in all sizes for these objects.

The kappa coefficient calculated for the inter-observer agreement was not statistically significant for $<1 \mathrm{~cm}$ glass, $<1 \mathrm{~cm}$ porcelain, $<1 \mathrm{~cm}$ plastic, $<1 \mathrm{~cm}$ wood, $<1 \mathrm{~cm}$ iron, $<1 \mathrm{~cm}$ fishbone, $1-3 \mathrm{~cm}$ fishbone, and 3-5 cm fishbone $(p>0.05)$. The kappa coefficient calculated for the inter-observer agreement was statistically significant for other FBs.

\section{Discussion}

On the sonographic examination of FBs implanted into the superficial soft tissue, the posterior shadowing or strengthening varies depending on the angle between the object and the probe. The posterior shadow becomes more prominent if the object and the probe are parallel to each other. Therefore, it is important to make a multiplanar evaluation. In our study, we performed 2-planar imaging. The smaller the size of the FBs, the more difficult it is to recognize them by US [6]. In this study, we evaluated the detectability of objects according to their dimensions. Comparison of different sizes are not available in the current literature.

In our study, the sensitivity, specificity, and accuracy were very good for the diagnosis of FBs. The sensitivity and accuracy were low for the cactus thorn. Cactus thorns may not be detected due to their thickness, as in our study.

All the FBs examined in our study were hyperechoic (Figure 1). A hypoechoic line between the 2 hyperechoic linear lines was observed in the plastic FBs (Figure 2). We thought that this was due to the layered structure of plastic bodies formed during the production processes. Posterior strengthening was determined in FBs, which was more prominent in porcelain, walnut shell, peanut shell, and pellet.

Detection and localization can be difficult with radiography. US, CT, and MRI are other methods for the evaluation of FBs. CT is ionizing radiation exposure. MRI is expensive [7].

There are many studies evaluating in-vivo and invitro detection of non-radiopaque FBs by ultrasonography. Bray et al. found that the sensitivity of US was $94 \%$ and the specificity was $99 \%$ in their study conducted with $1 \times 4 \mathrm{~mm}$ and $2 \times 5 \mathrm{~mm}$ sized wood, glass, and metal FBs implanted on the fingers of cadavers. They reported the 
Table 1. Sensitivity, specificity, positive predictive value, and negative predictive value were calculated for each materiel

\begin{tabular}{|l|c|c|c|c|c|}
\hline Material & $\begin{array}{c}\text { Sensitivity } \\
(\%)\end{array}$ & $\begin{array}{c}\text { Specificity } \\
(\%)\end{array}$ & $\begin{array}{c}\text { Positive } \\
\text { predictive } \\
\text { value (\%) }\end{array}$ & $\begin{array}{c}\text { Negative } \\
\text { predictive } \\
\text { value (\%) }\end{array}$ & $\begin{array}{c}\text { Test } \\
\text { validity } \\
(\%)\end{array}$ \\
\hline$<1$ cm glass & 95.0 & 92.5 & 92.6 & 94.8 & 93.7 \\
\hline $1-3 \mathrm{~cm}$ glass & 100.0 & 92.5 & 93.0 & 100.0 & 96.2 \\
\hline $3-5 \mathrm{~cm}$ glass & 100.0 & 92.5 & 93.0 & 100.0 & 96.2 \\
\hline $\begin{array}{l}<1 \mathrm{~cm} \\
\text { porcelain }\end{array}$ & 100.0 & 90.0 & 90.9 & 100.0 & 95.0 \\
\hline $\begin{array}{l}\text { 1-3 cm } \\
\text { porcelain }\end{array}$ & 100.0 & 92.5 & 93.0 & 100.0 & 96.2 \\
\hline $\begin{array}{l}3-5 \mathrm{~cm} \\
\text { porcelain }\end{array}$ & 100.0 & 92.5 & 93.0 & 100.0 & 96.2 \\
\hline$<1 \mathrm{~cm}$ plastic & 95.0 & 92.5 & 92.6 & 94.8 & 93.7 \\
\hline $1-3 \mathrm{~cm}$ plastic & 100.0 & 92.5 & 93.0 & 100.0 & 96.2 \\
\hline $3-5 \mathrm{~cm}$ plastic & 100.0 & 92.5 & 93.0 & 100.0 & 96.2 \\
\hline$<1 \mathrm{~cm}$ wood & 95.0 & 92.5 & 92.6 & 94.8 & 93.7 \\
\hline $1-3 \mathrm{~cm}$ wood & 100.0 & 92.5 & 93.0 & 100.0 & 96.2 \\
\hline $3-5 \mathrm{~cm}$ wood & 100.0 & 92.5 & 93.0 & 100.0 & 96.2 \\
\hline $\begin{array}{l}<1 \mathrm{~cm} \\
\text { pencil-tip }\end{array}$ & 100.0 & 92.5 & 93.0 & 100.0 & 96.2 \\
\hline $\begin{array}{l}1-3 \mathrm{~cm} \\
\text { pencil-tip }\end{array}$ & 100.0 & 92.5 & 93.0 & 100.0 & 96.2 \\
\hline $\begin{array}{l}3-5 \mathrm{~cm} \\
\text { pencil-tip }\end{array}$ & 100.0 & 92.5 & 93.0 & 100.0 & 96.2 \\
\hline $\begin{array}{l}<1 \mathrm{~cm} \text { chicken } \\
\text { bone }\end{array}$ & 100.0 & 92.5 & 93.0 & 100.0 & 96.2 \\
\hline
\end{tabular}

\begin{tabular}{|l|c|c|c|c|c|}
\hline Material & $\begin{array}{c}\text { Sensitivity } \\
(\%)\end{array}$ & $\begin{array}{c}\text { Specificity } \\
(\%)\end{array}$ & $\begin{array}{c}\text { Positive } \\
\text { predictive } \\
\text { value (\%) }\end{array}$ & $\begin{array}{c}\text { Negative } \\
\text { predictive } \\
\text { value (\%) }\end{array}$ & $\begin{array}{c}\text { Test } \\
\text { validity } \\
(\%)\end{array}$ \\
\hline $\begin{array}{l}\text { 1-3 cm chicken } \\
\text { bone }\end{array}$ & 100.0 & 92.5 & 93.0 & 100.0 & 96.2 \\
\hline $\begin{array}{l}3-5 \text { cm chicken } \\
\text { bone }\end{array}$ & 100.0 & 92.5 & 93.0 & 100.0 & 96.2 \\
\hline$<1$ cm iron & 92.5 & 92.5 & 92.5 & 92.5 & 92.5 \\
\hline $1-3$ cm iron & 100.0 & 92.5 & 93.0 & 100.0 & 96.2 \\
\hline $3-5$ cm iron & 100.0 & 92.5 & 93.0 & 100.0 & 96.2 \\
\hline $\begin{array}{l}1-3 \mathrm{~cm} \text { peanut } \\
\text { shell }\end{array}$ & 100.0 & 92.5 & 93.0 & 100.0 & 96.2 \\
\hline $\begin{array}{l}<1 \text { cm walnut } \\
\text { shell }\end{array}$ & 100.0 & 92.5 & 93.0 & 100.0 & 96.2 \\
\hline $\begin{array}{l}1-3 \mathrm{~cm} \text { walnut } \\
\text { shell }\end{array}$ & 100.0 & 92.5 & 93.0 & 100.0 & 96.2 \\
\hline $\begin{array}{l}3-5 \mathrm{~cm} \text { walnut } \\
\text { shell }\end{array}$ & 100.0 & 92.5 & 93.0 & 100.0 & 96.2 \\
\hline Rose spiked & 100.0 & 92.5 & 93.0 & 100.0 & 96.2 \\
\hline Cactus spurs & 5.0 & 92.5 & 40.0 & 92.5 & 48.7 \\
\hline Pellets & 100.0 & 92.5 & 93.0 & 100.0 & 96.2 \\
\hline$<1 \mathrm{~cm}$ fish bone & 77.5 & 92.5 & 91.1 & 80.4 & 82.5 \\
\hline $1-3 \mathrm{~cm}$ fish bone & 85.0 & 92.5 & 91.8 & 86.0 & 88.7 \\
\hline $3-5 \mathrm{~cm}$ fish bone & 82.5 & 92.5 & 91.6 & 84.0 & 87.5 \\
\hline $1-3 \mathrm{~cm}$ staples & 100.0 & 92.5 & 93.0 & 100.0 & 96.2 \\
\hline
\end{tabular}

sensitivity for small metals as 79\%, 95\% for small wood, 93\% for small glass, and $100 \%$ for large wood and glass FBs implanted in the phalanges. When it comes to the FBs implanted in the palmar surface, the sensitivity was reported as $77 \%$ for small glass FBs and $100 \%$ for all other FBs [8]. Similarly to our results, US sensitivity increased as the size of the FB increased in this study. Many studies have been conducted with US on non-radiopaque objects, whereas none of these studies have evaluated the size of the FBs. In these studies, sensitivity and specificity values were found to be high for the detection of FBs by US.

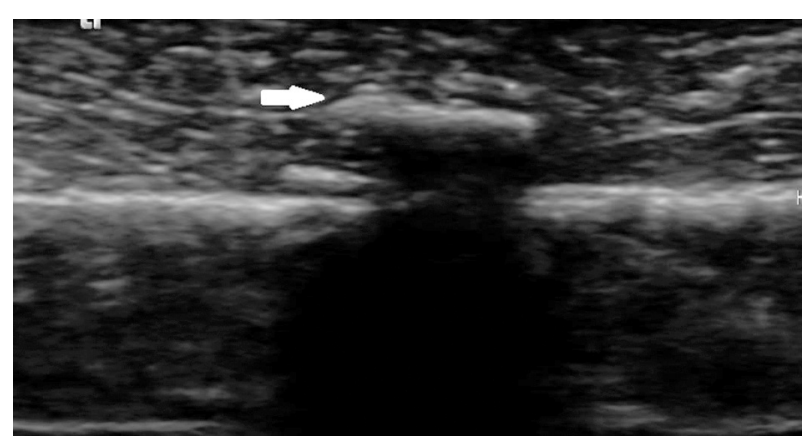

Figure 1. A 1-3 cm glass phantom in pieces of chicken fillet on ultrasonography was hyperechoic (white arrow) with posterior acoustic shadowing

In a study on phantoms by Driskell et al., radiologists and emergency medicine doctors evaluated phantoms in which $1 \mathrm{~mm}, 2 \mathrm{~mm}$, and $3 \mathrm{~mm}$ wooden FBs had been implanted [8]. The sensitivity and specificity values were not different between the radiologists and emergency de-

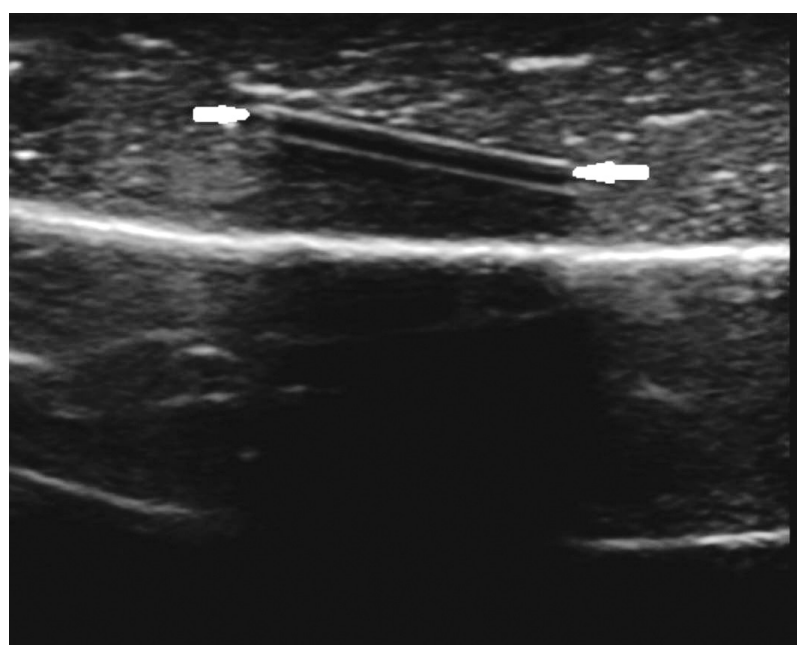

Figure 2. A plastic phantom in pieces of chicken fillet on ultrasonography, a hypoechoic line (white arrows) can be seen between the 2 hyperechoic linear lines 
partment physicians for the wooden FBs [9]. Similarly, in our study, there was a perfect fit between the results of US evaluation by the radiologist and emergency medicine doctors for the wooden FBs. But we also evaluated FBs other than wood, and there was no statistically significant difference between the observers for $<1 \mathrm{~cm}$ glass, $<1 \mathrm{~cm}$ porcelain, $<1 \mathrm{~cm}$ plastic, $<1 \mathrm{~cm}$ wood, $<1 \mathrm{~cm}$ iron, $<1 \mathrm{~cm}$ fishbone, $1-3 \mathrm{~cm}$ fishbone, and $3-5 \mathrm{~cm}$ fishbone.

Honton et al. reported that soft-tissue FBs appear hyperechoic on ultrasonographic examination [10]. In our study, all FBs were hyperechoic. In the case of a lack of strong posterior shadowing in the sonographic examination of FBs, muscle fibres may cause misinterpretations because they also cause hyperechogenicity on the US. In the distinction of these 2 conditions, following the muscle fibres longitudinally would be helpful.

In the study of Demiralp et al. on FBs in intraoral localization conducted with phantoms, they reported a hypoechoic halo around the FBs in the case of chicken bone fragment, root, stone, tooth enamel, amalgam, and orthodontic wire stab [11]. In our study, only the chicken bone fragment was examined among these FBs, and we did not observe a hypoechoic halo around it.

The phantoms created did not contain bone tissue. This was the main limitation of our study. Investigators in future studies may also wish to include a larger number of each individual FB to increase the power of the study. Because the study was designed in-vitro, we could not evaluate the findings such as fibrosis and inflammation occurring around the surrounding tissue in-vivo. We evaluated objects in a multiplanar fashion but did not evaluate in which plain they were better visualized. Furthermore, we did not use modern US techniques such as elastography, which was another limitation [12].

Finally, we only used a linear probe. Greater phantoms could be evaluated using a convex probe.

\section{Conclusions}

Inconclusion, as the size of the FBs increases, the diagnostic value of US increases in detecting soft tissue FBs. In the evaluation of soft-tissue FBs, US can be used as the first-line diagnostic tool in the practice of both radiologists and emergency medicine specialists.

\section{Conflict of interest}

The authors report no conflict of interest.

\section{References}

1. Fu Y, Cui LG, Romagnoli C, et al. Ultrasound-guided removal of retained soft tissue foreign body with late presentation. Chin Med J 2017; 130: 1753-1754.

2. Bradley M. Image-guided soft-tissue foreign body extraction - success and pitfalls. Clin Radiol 2012; 67: 531-534.

3. Manthey DE, Storrow AB, Milbourn JM, Wagner BJ. Ultrasound versus radiography in the detection of soft-tissue foreign bodies. Ann Emerg Med 1996; 28: 7-9.

4. Saul T, Siadecki SD, Rose G, et al. Ultrasound for the evaluation of soft tissue foreign bodies before and after the addition of fluid to the surrounding interstitial space in a cadaveric model. Am J Emerg Med 2016; 34: 1779-1782.

5. Tseng HJ, Hanna TN, Shuaib W, et al. Imaging foreign bodies: ingested, aspirated, and inserted. Ann Emerg Med 2015; 66: 570-582.

6. Shiels II WE, Babcock DS, Wilson JL, et al. Localization and guided removalof soft-tissue foreign bodies with sonography. AJR Am J Roentgenol 1990; 155: 1277-1278.

7. Shrestha D, Sharma UK, Mohammad R, Dhoju D. The role of ultrasonography in detection and localization of radiolucent foreign body in soft tissues of extremities. JNMA J Nepal Med Assoc 2009; 48: 5-9.

8. Bray PW, Mahoney JL, Campbell JP. Sensitivity and specificity of ultrasound in the diagnosis of foreign bodies in the hand. J Hand Surg Am 1995; 20: 661-666.

9. Driskell DL, Gillum JB, Monti JD, Cronin A. Ultrasound evaluation of soft-tissue foreign bodies by US Army medics. J Med Ultrasound 2018; 26: 147-152.

10. Horton LK, Jacobson JA, Powell A, Fessell DP, Hayes CW. Sonography and radiography of soft-tissue foreign bodies. AJR Am J Roentgenol 2001; 176: 1155-1159.

11. Demiralp KO, Orhan K, Kurşun-Çakmak EŞ, et al. Comparison of cone beam computed tomography and ultrasonography with two types of probes in the detection of opaque and non-opaque foreign bodies. Med Ultrason 2018; 20: 467-474.

12. Taljanovic MS, Gimber LH, Becker GW, et al. Shear-wave elastography: basic physics and musculoskeletal applications. Radiographics 2017; 37: 855-870. 